\title{
Trombose venosa em criança
}

Venous thrombosis in children

Maria Emília dos Santos'; Braz José do Nascimento Júnior²; Maria da Conceição Barros Correia ${ }^{3}$; Vera Lúcia de Menezes Lima4; Simone de Campos Vieira Abib ${ }^{5}$; Luana Cassandra Breitenbach Barroso Coelho ${ }^{6}$

\section{unitermos}

Fator V de Leiden

Trombose venosa profunda

Resistência à proteína C ativada

\section{resumo}

A incidência de trombose venosa profunda (TVP) em crianças ( 0 a 18 anos) é baixa. $O$ objetivo desse trabalho é estudar uma criança de 12 anos que, após um trauma, apresentou TVP. Atividades de proteína $\mathrm{C}$, proteína $\mathrm{S}$, antitrombina e resistência à proteína $\mathrm{C}$ ativada (RPCA) foram analisadas em coagulômetro. $\mathrm{O}$ fator $\mathrm{V}$ de Leiden (FVL) foi pesquisado. O paciente e seu pai (assintomático até o momento) foram heterozigotos para FVL e sua mãe foi homozigota normal. Concluímos que o FVL associado a outras condições clínicas tende a ser multiplicativo para a ocorrência de trombose, que é multifatorial. abstract

The incidence of deep venous thrombosis (DVT) in children (0-18 years old) is low. The aim of this study was to investigate the case of a 12 year-old child that had DVT after a trauma. Protein C and protein S activities, antithrombin and resistance to activated protein $\mathrm{C}$ were analyzed in coagulometer. Factor $V$ Leiden (FVL) was studied. The patient and his father were heterozygotes for FVL. His mother was normal homozygote. We concluded that the presence of FVL associated with other medical conditions tends to multiply the occurrence of thrombosis, which is a multifactorial disease.

\section{key words}

Factor V Leiden

Deep venous thrombosis

Resistance to activated protein $\mathrm{C}$

1. Doutora; biomédica da Fundação de Hematologia e Hemoterapia de Pernambuco (HEMOPE).

2. Mestre em Bioquímica; doutorando em Cirurgia e Experimentação da Universidade Federal de São Paulo (UNIFESP).

3. Médica hematologista; phD em Medicina Tropical pela Universidade Federal de Pernambuco (UFPE); professora de Hematologia para curso médico da UFPE.

4. PhD; doutora em Bioquímica; professora adjunta do Departamento de Bioquímica da UFPE.

5. Doutora em Cirurgia Pediátrica; professora afiliada de ensino da disciplina Técnica Operatória e Cirurgia Experimental do Departamento de Cirurgia da Escola Paulista de Medicina da Universidade Federal de São Paulo (EPM/UNIFESP).

6. PhD; doutora em Bioquímica; professora adjunta do Departamento de Bioquímica da UFPE. 


\section{Introdução}

Doenças hereditárias causadas por mutações em fatores da coagulação são causadoras de enfermidades trombofílicas. Entre elas, tem-se o fator $\mathrm{V}$ de Leiden ( $\mathrm{FVL})$, considerado a principal causa de trombofilia hereditária( ${ }^{(4,5)}$. O fator $\mathrm{V}$ ou fator Lábil, presente em indivíduos normais, é uma globulina, glicoproteína de $330 \mathrm{KDa}$, sintetizada em hepatócitos e megacariócitos. Contém 10\% a 20\% de carboidratos e é inativado pela remoção da penúltima galactose. No organismo esse fator é ativado pela trombina, formando, juntamente com o fator Xa e íons cálcio, o complexo chamado protrombinase. Na superfície fosfolipídica da membrana plaquetária, o complexo transforma a protrombina em trombina ${ }^{(10)}$.

Existem evidências claras de que o processo é influenciado pela complexa interação de fatores genéticos e ambientais, que recebem a denominação genérica de fatores de risco. A caracterização dos fatores de risco para o tromboembolismo venoso (TEV) representa etapa fundamental para compreensão da patogênese dessa entidade clínica. Fatores de risco adquiridos para TEV incluem idade avançada, imobilização prolongada, cirurgia, fratura óssea, uso de contraceptivo oral, gestação, puerpério, neoplasias e trauma ${ }^{(3,6,11)}$.

A resistência à proteína $C$ ativada (RPCA) é, em 95\% dos casos, decorrente de uma mutação no fator $\mathrm{V}$ da coagulação: uma transição guanina $\rightarrow$ adenina na posição 1691 do gene, resultando na substituição de arginina (R) por glutamina (Q) na posição do aminoácido 506 (que constitui sítio de clivagem da proteína $C$ ativada na molécula do fator $\mathrm{V}$, servindo de mecanismo anticoagulante). $\mathrm{O}$ fator $\mathrm{V}$ resultante é resistente à neutralização mediada pela proteína $C$ ativada, o que resulta no fenótipo de RPCA. O FVL é associado a um estado de hipercoagulabilidade e susceptibilidade aumentada para ocorrência de TEV. O FVL aumenta o risco de TEV em aproximadamente três a oito vezes em heterozigose e 50 a 100 vezes em homozigose. A mutação é altamente prevalente e pode ser investigada por ensaio baseado no tempo de tromboplastina parcial ativada (TTPA), por plasma deficiente em fator $V$ ou por técnicas de análise gênica baseadas em ampliação por reação em cadeia da polimerase (PCR) do exon 10 do fator $V^{(1,6,12)}$. A prevalência do $F V L$ é de $2 \%$ a $7 \%$ em populações caucasoides e é identificado em $20 \%$ a $50 \%$ nos pacientes acometidos de TEV(2).

Geralmente o evento tromboembólico ocorre pouco depois do trauma ${ }^{(7,14)}$. A literatura também registra a ocor- rência de trombose espontânea em ratos homozigotos para o fator $\mathrm{V}$ de Leiden ${ }^{(2)}$.

\section{Relato do caso}

O paciente tinha 12 anos de idade quando apresentou tosse seca, dispneia, picos febris e edema de membro inferior esquerdo horas após contusão futebolística. $\mathrm{O}$ diagnóstico foi de trombose venosa profunda com 13 dias de internação. Após alta médica, o paciente desenvolveu complicação pós-trombótica na forma de úlcera varicosa e o membro permaneceu edemaciado. O avô paterno teve morte súbita por trombose, porém os avós maternos não registraram episódio de trombose até o momento.

\section{Materiais e métodos}

A entrevista só ocorreu após consentimento livre e esclarecido dos pacientes ou responsáveis, segundo o código de Helsinque (2001).

Os exames foram realizados no Laboratório de Biologia Molecular da Fundação de Hematologia e Hemoterapia de Pernambuco (HEMOPE). Os kits dos reagentes comerciais (ativador de proteína C, fator Xa bovino, plasma humano deficiente em fator $V$ e controle de proteína $S$ ) foram adquiridos em Barcelona, Espanha, na Instrumentation Laboratory, a enzima de restrição utilizada foi a Taq Polimerase (Gibco-BRL, EUA), os Primers e tampões foram da Pharmacia, Brasil, marcadores de peso molecular,Gibco-BRL, EUA, e o DNA foi extraído por técnicas convencionais utilizando-se kits comerciais (Gentra Systems, Inc., Minneapolis, EUA).

Uma amostra de $9 \mathrm{ml}$ de sangue venoso foi extraída de veia periférica e colocada em tubo estéril, tipo Vacutainer, com anticoagulante ácido etilenodiaminotetracético (EDTA).

Plasma pobre em plaquetas foi preparado por centrifugação a $3.000 \mathrm{~g}$ durante 20 minutos, a $4^{\circ} \mathrm{C}$. As amostras foram colocadas em tubos de poliestireno, armazenadas a $70^{\circ} \mathrm{C} \mathrm{e}$ descongeladas imediatamente antes do procedimento.

Os ensaios para determinação dos genótipos fator $V$ G1691A e protrombina G20210A foram feitos por reação em cadeia da polimerase (PCR) e a análise por enzimas de restrição. As atividades de proteína C (PC) e antitrombina (AT) foram medidas em um analisador ACL 7000 (Instrumentation Laboratory), utilizando-se substratos cromogênicos (Instrumentation Laboratory). O antígeno proteína S (PS) 
livre, PS total e antígeno PC foram medidos utilizando kits comerciais (Gentra Systems, Inc., Minneapolis, EUA).

Os padrões eletroforéticos para o FVL esperados após o tratamento com as enzimas de restrição foram normais 120 e 42 pares de base (pb); heterozigotos 162, 120 e 42 $\mathrm{pb}$; e homozigotos $162 \mathrm{pb}$.

Os padrões eletroforéticos esperados para mutação da protrombina G20210A foram normais 322 e 23 pb; heterozigotos 345, 322 e 23 pb; e homozigotos: 345 pb.

\section{Resultados}

O estudo do tempo de tromboplastina parcial ativada revelou resultado normal. As avaliações das atividades plasmáticas de proteína $C$, proteína $S$, antitrombina e a dosagem do fibrinogênio apresentaram-se dentro da faixa de normalidade (Tabela 1).

Atividades plasmáticas de proteína C, proteína $\mathrm{S}$, antitrombina e dosagem de fibrinogênio do paciente com trombose e

\section{Tabela 1 seus pais}

\begin{tabular}{lcccc}
\hline & $\begin{array}{c}\text { Proténa } \\
\mathrm{C}(\%)\end{array}$ & $\begin{array}{c}\text { Proteína } \\
\text { S (\%) }\end{array}$ & Antitrombina & Fibrinogênio \\
Paciente & 65 & 71 & 100 & 2,66 \\
Pai & 121 & 141 & 93 & 2,08 \\
Mãe & 137 & 125 & 108 & 2,99
\end{tabular}

O paciente e seu genitor apresentaram RPCA, logo, heterozigotos para FVL. A genitora teve resultado negativo para RPCA (Tabela 2).

\section{Características clínicas e laboratoriais de uma família com RPCA devido à}

Tabela 2 mutação arginina $\rightarrow$ glutamina

\begin{tabular}{|c|c|c|c|c|}
\hline $\begin{array}{l}\text { Membro } \\
\text { da família }\end{array}$ & $\begin{array}{l}\text { História de } \\
\text { trombose }\end{array}$ & $\begin{array}{l}\text { Razão } \\
\text { RPCA* }\end{array}$ & $\begin{array}{c}\text { Situação } \\
\text { do alelo } \\
\text { Arginina } \rightarrow \\
\text { Glutamina }\end{array}$ & $\begin{array}{c}\text { Relação } \\
\text { ao limite } \\
\text { inferior } \\
\text { normal } \\
\text { para } \\
\text { RPCA } \\
(\%)\end{array}$ \\
\hline Mãe & Não & 2.45 & Normal & +29 \\
\hline Pai & Não & 1.74 & Heterozigoto & -21 \\
\hline Paciente & Sim & 1.6 & Heterozigoto & -27 \\
\hline
\end{tabular}

*Valores normais entre 2,2 e 4,6 no homem e entre 1,9 e 4,4 na mulher. $\mathrm{RPCA}$ : resistência à proteína $\mathrm{C}$ ativada.
O paciente e seu genitor apresentaram padrões de migração em eletroforese em gel de agarose na pesquisa do FVL semelhantes: 162, 12042 pb. A migração do DNA materno apresentou duas bandas: 120 e 42 pb (Figura 1).

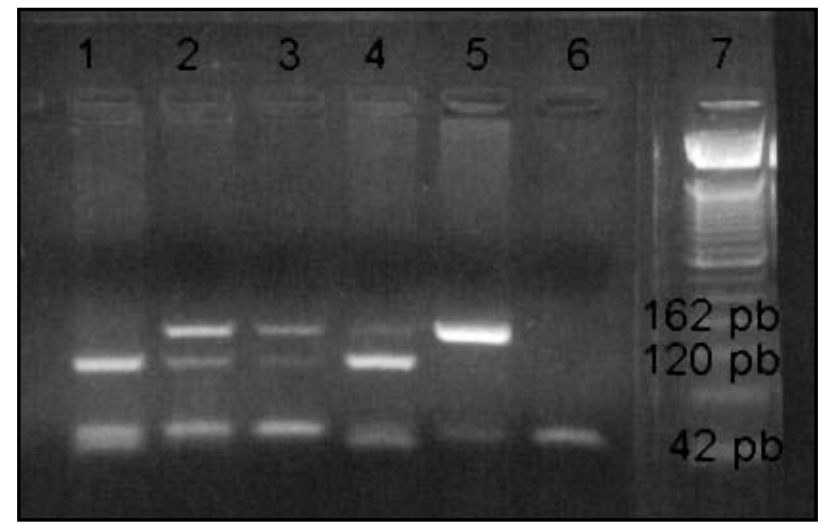

Figura 1 - Pesquisa do fator V de Leiden na criança e em seus pais. Raia 1: mãe; raia 2: pai; raia 3: paciente; raia 4: heterozigoto-controle; raia 5: não-digerido; raia 6: água Milli Q; eaia 7: marcador de peso molecular

A pesquisa do FVL no paciente e nos seus genitores evidenciou resultados compatíveis com a presença do alelo fator V R506Q em heterozigose para o paciente e seu pai(7) e ausência do FVL na sua mãe (Figura 1).

Para pesquisa da mutação G20210A da protrombina, que é a segunda causa de trombose hereditária ${ }^{(13)}$, os três membros da família apresentaram padrões normais de migração com 322 e 23 pb. Não foi identificada a mutação G20210A da protrombina no paciente estudado ou em seus pais (Figura 2).

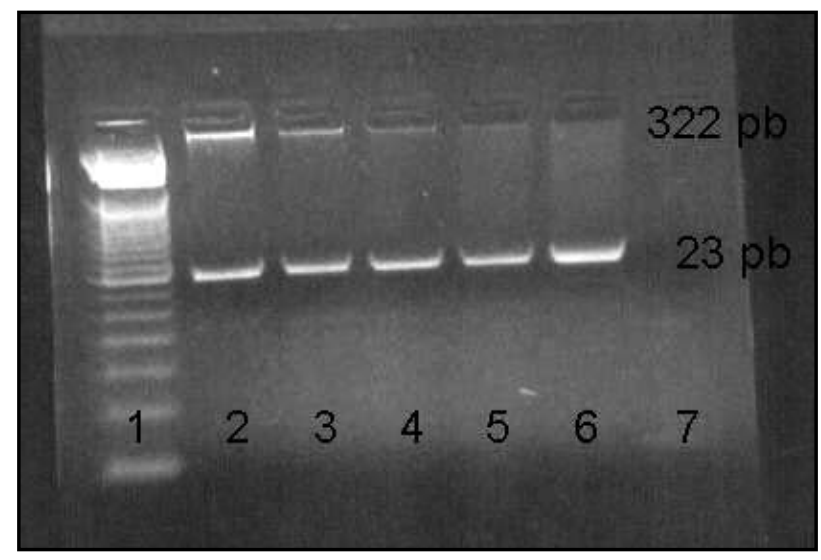

Figura 2 - Pesquisa da mutação G20210A da protrombina no paciente com trombose venosa profunda e em seus pais. Raia 1: marcador de peso molecular; raia 2: mãe; raia 3: pai. raia 4: paciente, raia 5: controle-negativo; raia 6: não-digerido; raia 7: água Milli $\mathrm{Q}$ 


\section{Discussão}

A metodologia utilizada neste trabalho é de uso padronizado em laboratório de análise clínicas, com kits reagentes comercialmente disponíveis no mercado. A identificação das mutações nas deficiências hereditárias de anticoagulantes não é praticável por apresentar considerável heterogeneidade genética ${ }^{(8)}$.

Não foi identificada a mutação da protrombina no paciente ou em seus pais. Este achado teria relação com a evolução clínica do paciente e seu pai, até agora assintomático. Não ocorreu recorrência de trombose no paciente até o momento. $\mathrm{O}$ risco de recorrência de trombose venosa em heterozigotos para o FVL parece ser semelhante aos não-portadores da mutação( ${ }^{(4)}$.

Cerca de $25 \%$ dos portadores do FVL desenvolvem trombose antes dos 40 anos. Fatores ambientais e adquiridos, como o pós-operatório cirúrgico e o trauma, têm papel desencadeante. Os membros inferiores e a pelve são os locais mais frequentemente acometidos pelo tromboembolismo venoso. Nos Estados Unidos, a sua prevalência é de 600 mil casos por ano, sendo responsável por $5 \%$ a $10 \%$ de todas as mortes hospitalares ${ }^{(16)}$. O paciente sofreu trombose venosa profunda de membro inferior esquerdo.
Portadores do FVL em heterozigose têm aumento de sete a oito vezes no risco para trombose venosa, enquanto em homozigose o risco sobe para oitenta vezes ${ }^{(9)}$. O paciente apresentou FVL em heterozigose e sofreu um episódio de trombose muito jovem. Durante a hospitalização o paciente fez uso de varfarina sódica (Marevan) e heparina. Até o momento desta publicação, está sob acompanhamento médico e sob uso de cumarínico com ajustes periódicos, de acordo com o INR. Não apresenta registro de recorrência de trombose.

Os pacientes com o FVL têm menor risco para trombose que os portadores de deficiências de proteína $C$, proteína $S$ e antitrombina e podem permanecer assintomáticos, apresentando um primeiro episódio tromboembólico depois dos 60 anos $^{(14)}$. O avô paterno do paciente sofreu infarto fatal aos 58 anos e poderia ser portador do FVL.

O paciente estudado teve trombose após um trauma, episódios de trombose venosa profunda e embolia pulmonar são muito frequentes após traumas e cirurgias, causando morbidade e mortalidade na população(7, 14). A associação entre o episódio de trauma e a presença do FVL em heterozigose provavelmente precipitaram o evento trombótico neste jovem paciente. Mecanismos protetores individuais precisam ser pesquisados para explicar o fato do seu pai ainda não ter tido trombose.

\section{Referências}

1. CARVALHO, E. B. et al. Rastreamento familiar do fator $V$ de Leiden: a importância da detecção de portadores heterozigotos. Rev. Bras. Hematol. Hemoter, v. 27, n. 2, 2005

2. CUI, J.; EITZMAN, D. T.; WESTRICK, R. J. Spontaneous thrombosis in mice carrying the factor $\mathrm{V}$ Leiden mutation. Blood, v. 96, n. 13, p. 4222-26, 2000.

3. CUSHMAN, M. et al. Associations of the $\beta$-Fibrinogen Hae III and Factor XIII Val34Leu Gene Variants with Venous Thrombosis. Thromb Res. v. 121, n. 3, p. 339-45, 2007

4. DE STEFANO, V. et al. The risk of recurrent deep venous thrombosis among heterozygous carriers of both factor $\checkmark$ Leiden and G20210A prothrombin mutation. N Engl J Med, v. 341, n. 11, p. 801-5, 1999.

5. DI MICCO, B. et al. SV-IV Peptide1-16 reduces coagulant power in normal Factor $V$ and Factor $V$ Leiden. J Trans/ Med, v. 5, n. 69, p. 5876-79, 2007.

6. FRANCO, R. F. et al. Trombofilias Hereditárias. Rev Med Ribeirão Preto, v. 34, n. 3/4, p. 248-57, 2001.
7. GLOTZBECKER, M. P. et al. Surgeon Practices Regarding Postoperative Thromboembolic Prophylaxis After HighRisk Spinal Surgery. Spine, v. 33 n. 26, p. 2915-21, 2008.

8. GREAVES, M.; BAGLIN, T. Laboratory testing for heritable thrombophilia: impacto on clinical management of thrombotic disease. Brit J Haematol, v. 109, n. 4, p.699-3, 2000.

9. LENS, D.; OTERO, A. M.; COTIC, G. Diagnóstico molecular de fatores protrombóticos: primeiros casos de fator $V$ Leiden y protrombina g20210a em Uruguay. Rev med del Uruguay, v. 16, n. 1, p. 39-44, 2000.

10. LOURENÇO, D. M. Mecanismos envolvidos na formação do trombo. Rev Soc Cardiol Est São Paulo. v. 3, p. 54-61, 1997.

11. MELTZER, M. E etal. Synergistic Effects of Hypofibrinolysis and Genetic and Acquired Risk Factors on the Risk of a First Venous Thrombosis. Plos Med, v. 5, n. 5, p. 0001-9, 2008. 
12. NOJIMA, J. et al. Acquired activated protein C resistance associated with IgG antibodies against $\beta 2$-gly I and prothrombin as a strong risk factor for venous thromboembolism. Clinic Chemist, v. 51. 545-52, 2005.

13. RAMOS, C. P. S. et al. Protrombina mutante em indivíduos sob investigação de trombofilia. J Bras Patol Med Lab, v. 44, n. 2, 2008.

14. RUDDY, J. M. et al. Incidental pulmonary embolism identified on chest CT during initial trauma evaluation. Am Surg, v. 74, n. 12, p. 1146-50, 2008.

15. VERDU, A.; CAZORLA, M. R.; GRANADOS, M. A. Basilar artery thrombosis in a child heterozygous for factor V Leiden mutation. Pediat Neurol, v. 24, n. 1, 2001.

16. VITERBO, J. F. et al. Profilaxia e tratamento da tromboembolia pulmonar per-operatória. A Med Port, v. 18 , p. 209-20. 2005. 